\title{
CVD Synthesis of HTSC Films Using Volatile Coordination Compounds
}

\author{
S.V. Volkov, V.Y. Zub, O.N. Balakshina and E.A. Mazurenko \\ Institute of General and Inorganic Chemistry of National Academy of Sciences of Ukraine 32/34, Palladina \\ prosp., Kiev-142, UA-252142, Ukraine
}

\begin{abstract}
Thin HTSC films of $\mathrm{YBa}_{2} \mathrm{Cu}_{3} \mathrm{O}_{7-x}$ with high c-axis orientation have been grown using PE MOCVD technique and adducts of copper, yttrium and barium acetylacetonate with $\alpha, \alpha^{4}$ - dipyridyl as precursors. In-situ films were deposited in $\mathrm{N}_{2}$ and $\mathrm{O}_{2}$ gas reactant mixture at reduced substrate temperatures. HTSC films prepared on $\mathrm{SrTiO}_{3}, \mathrm{ZrO}_{2}(\mathrm{Y})$ and $\mathrm{MgO}$ substrates have rather high electric characteristics (e.g. $\mathrm{j}_{\mathrm{r}} \approx 10^{4}-10^{5} \mathrm{~A} / \mathrm{cm}^{2}$ ). The problem of $\beta$-diketonate adducts using as precursors for plasma enhanced chemical vapor deposition of superconductive films was discussed.
\end{abstract}

\section{INTRODUCTION}

Recently various chemical vapor deposition techniques have become widely used for production of different functional materials. The main advantages of CVD processes are: simplified apparatus, deposition of coatings (from epitaxial layers to thick films) on latge surfaces with intricate geometry, compositional control and thus a flexible preparation of films with specific composition, structure, physical, chemical and mechanical properties $[1,2,3]$. Suitability of CVD methods is due to significant progtess in chemical synthesis processes providing a wide range of volatile thermal stable metal compounds. Thus metalorganic chemical vapor deposition (MO CVD) is successfully applied for fabrication of high quality, uniform high temperature superconductive films (HTSC).

In the majority of published works dealing with preparation of $\mathrm{Y}-\mathrm{Ba}-\mathrm{Cu}-\mathrm{O}$ and $\mathrm{Bi}-\mathrm{Sr}, \mathrm{Ca}-\mathrm{Cu}-\mathrm{O} \mathrm{HTSC}$ films via MO CVD such chelate compounds as metal $\beta$-diketonates have been used as precursors [4-14]

It should be notified that progress in synthesis of high quality HTSC materials still is dependent not on existing physical theoretical models of superconductivity but on rather simple physical and chemical regularities and phenomenological models. So it is essential to determine optimal deposition conditions (temperature, pressure, gas flow rates, etc.) and compositions of reactants (their chemical nature, mechanism of thermal decomposition, compositions of products, etc.)

Analysis of the works concerning preparation of HTSC films via different CVD techniques allows to highlight the following chemical problems in order to fabricate films with good characteristics: (1) selection of volatile compounds having sufficient yield of vapor pressure and the ability to gas phase transition without decomposition; (2) determination of optimal parameters of both the precursors thermal decomposition and formation of oxide phase with specific compositions [15].

In this paper we consider these problems applied to $\mathrm{YBa}_{2} \mathrm{Cu}_{3} \mathrm{O}_{7-x}$ films deposition. 


\section{SELECTION OF VOLATILE COMPOUNDS}

Since $\mathrm{YBa}_{2} \mathrm{Cu}_{3} \mathrm{O}_{7-x}$ superconductive phase has a very narrow uniform area even small compositional deviations from $\mathrm{Y}: \mathrm{Ba}: \mathrm{Cu}$ stoichiometric ratio cause the non-superconductive second phase condensation and consequent poor film properties. So the compounds used as precursors must have high enough vapor pressures at comparatively low temperatures, rather wide temperature range of thermal stability and ability to quantitative sublimation or evaporation. Thus only few metals organic compounds of yttrium, barium and copper could be used for 1-2-3 films deposition. Among them metal $\beta$-diketonates, their fluorine derivatives or $\mathrm{N}$-analogs are the most attractive.

In most cases the authors reported on application of 2,2,6,6-tetrametyl-3,5-heptadionates (dipivaloymethanates, DPM) of yttrium, barium and copper [4,7-10], such fluorine derivatives of $\beta$ diketone as $1,1,1,5,5,5$-hexafluoro-2,4-pentanedione, $1,1,1,2,2,3,3$,-heptanefluoro-7,7-dimetyl-4,6octanedione and 1,1,1-trifluoro-5,5-dimetyl-2,4-hexadione as precursors for deposition of HTSC films with high critical characteristics. These compounds have not been selected by chance. The examination of $\beta$-diketonates revealed that only copper formed with many $\beta$-diketones the thermal stable coordination compounds having different values of thermal stability dependent on diketone $\alpha$-substituents natures and high enough vapor pressures at temperatures of sublimation [16]. So the choice of volatile copper complex is not difficult.

Yttrium is able to form non-polymerized tris-compounds only with $\beta$-diketones with branched periphery (e.g., tret-butyl radicals) $[12,13]$. However even these rather volatile compounds become polymerized when heated and thus sharply decelerate sublimation (or evaporation) process. As a result composition of vapor phase changes and depositing oxide films become nonstoichiometric.

Since the ion radius of barium is larger and barium shows a lower tendency to coordination bonds formation than yttrium, barium compounds are easily polymerized [15]. Ba forms low volatile oligomer compicxes even with DPM and FOD ligands. Hence gas phase transition of $\mathrm{Ba}$ precursors and maintenance of stable component ratio is one of the keystones in the development of CVD process for $\mathrm{Y}(\mathrm{Zr}) \mathrm{Ba}_{2} \mathrm{Cu}_{3} \mathrm{O}_{7-\mathrm{x}}$ films fabrication.

Our examinations of metal $\beta$-diketonates chemistry [17] revealed the synthesis of theirs adducts to be possible way of this problem solution. Application of adducts with specific compositions not only improves thermal properties of compounds and increases their volatility but also permits to replace expensive and labor-consuming DPM and HFA by low cost and widely spread acetylacetone and trifluoroacetylacetone.

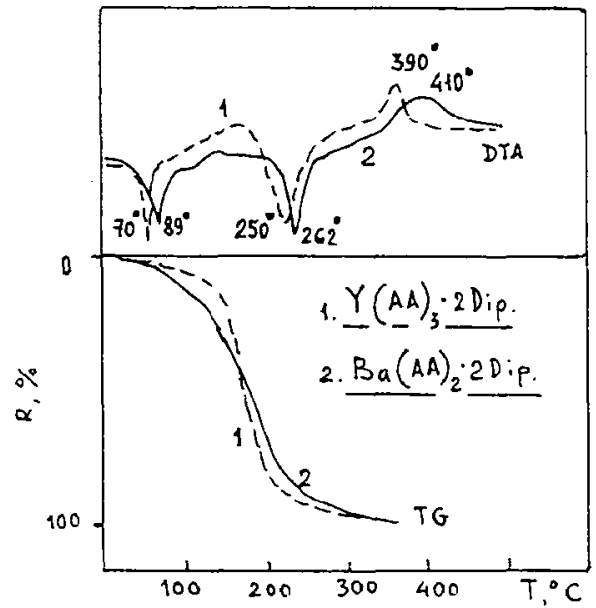

Figure 1: Derivatograms of adducts of yturium (1) and barium (2) acetylacetonates.

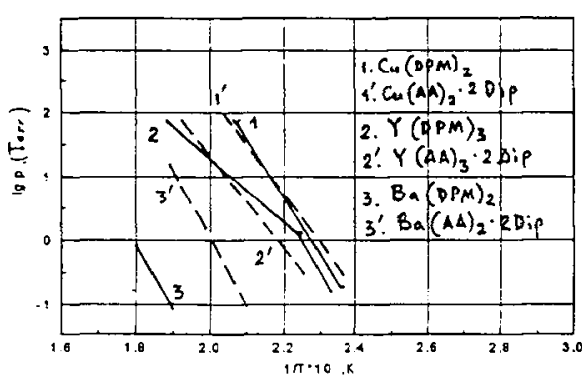

Figure 2: Vapor pressures versus temperatures for $\mathrm{Y}, \mathrm{Ba}$ and $\mathrm{Cu} \beta$ diketonates.

Figure 1 shows differential thermal analysis patterns of yttrium and barium acetylacetonate adducts synthesized in medium of monocarbon acids with $\alpha, \alpha^{6}-$ dipyridyl. The planar structure of $\alpha, \alpha^{2}$ - dipyridyl causes the growth of resonance stabilization of diketonate molecules 
It is evident from thermal analysis data and vapor pressure-temperature dependence (Fig.2) that formation of structure corresponding to the "island" type of molecules with fully shielded coordination center allows to suppress polymerization process, increases thermal stability of compounds and to maximize their quantitative sublimation.

Because adduct application permits to narrow the range of sublimation temperatures, the simplified apparatus consisting of only one evaporator instead of hot line formed by three evaporators can be used

\section{DEPOSITION CONDITIONS}

Besides the selection of coordination compounds the conditions of their thermolysis and simuitaneous formation of superconductive phase 1-2-3 are significant.

The examinations made by our group and some other authors $[14,18]$ revealed that applied r.f. plasma caused not only activation of $\beta$-diketonates but also oxygen activation and partial dissociation of nitrous oxide $\left(\mathrm{N}_{2} \mathrm{O}\right)$ to atomic oxygen (when the mixture of $\mathrm{N}_{2}$ and $\mathrm{O}_{2}$ was used as reactant gas). Hence in-situ formation of high temperature superconductive phase at significantly reduced deposition temperatures and without thermal annealing is flexible under these conditions.

\section{FORMATION OF HTSC FRMS}

Deposition of HTSC films was carried out in low-temperature plasma-chemical reactor with one evaporator for three isolated precursors - adducts of copper, yttrium and barium acetylacetonates with $\alpha, \alpha^{6}$ dipyridyl. Gas flows were transported by gas carrier to heated substrate through quartz tube no less than $300 \mathrm{~mm}$ long.

The optimal deposition conditions were determined as following: rate of gas-carrier flow saturated by acetylacetonate vapors was $0.35 \mathrm{l} / \mathrm{min}$; rate of reactant gas flow $\left(\mathrm{N}_{2}: \mathrm{O}_{2}\right.$ mixture with ratio $\left.1: 1\right)$ was 0.25 $1 / \mathrm{min}$; the substrate temperature was $620^{\circ} \mathrm{C}$; chamber pressures $110 \mathrm{~Pa}$; film growth rate was $1-4 \mu \mathrm{m} / \mathrm{h}$. teristics:

In-situ deposited textured $\mathrm{YBa}_{2} \mathrm{Cu}_{3} \mathrm{O}_{7-x}$ films with (001) preferred orientation have following charac-

\begin{tabular}{|c|c|c|c|}
\hline Substrate & $T c_{0}, \bar{K}$ & $T c_{e,} K$ & $\mathrm{j}_{\mathrm{c}}(\mathrm{T}=77 \mathrm{~K}), \mathrm{A} / \mathrm{cm}^{2}$ \\
\hline $\mathrm{SrTiO}_{3}$ & 90 & 88 & $\begin{array}{l}8 \cdot 10^{5}(\mathrm{H}=0) \\
3 \cdot 10^{4}(\mathrm{H}=2)\end{array}$ \\
\hline $\mathrm{ZrO}_{2}(\mathrm{Y})$ & 88 & 82 & $8 \cdot 10^{4}(\mathrm{H}=0)$ \\
\hline $\mathrm{MgO}$ & 80 & 70 & $2 \cdot 10^{4}(\mathrm{H}=0)$ \\
\hline
\end{tabular}

\section{CONCLUSIONS}

HTSC films of $\mathrm{YBa}_{2} \mathrm{Cu}_{3} \mathrm{O}_{7-x}$ with high $c$-axis orientation could be grown in-situ at rather low substrate temperatures $\left(540-560^{\circ} \mathrm{C}\right)$ without any high-temperature annealing when deposition parameters as r.f. plasma discharge power, the duration of gas components passing through plasma, composition of gas reactant would be further optimized.

\section{REFERENCES}

[1] Gribov B.G. et al., Osaxhdeniye plyonok i pokritiy razlozheniyem metalloorganicheskih soedineniy (Nauka, Moskva, 1981).

[2] Osazhdeniye iz gazovoy fazi (Atomizdat, Moskva, 1970).

[3] Blocher J.M. in Deposition Technologies for films and coatings (Park Ridge, New York, 1982) pp.335364.

[4] Shinohara K., Munakata F., Yamanaka M., Jap. J. Appl.Phys. 27 (1988)L1683-l1685.

[5] Yamane H. et al., Jap. J. Appl. Phys. 27 (1988)L1275-L1276.

[6] Yamane H. ey al., Appl. Phys. Lett. 53(1988)1548-1550.

[7] Ohnishi H. Harima H. et al. Jap. J. Appl. Phys. 29 (1990)L2041-L2044.

[8] Souc J., Machaidik D., et al.. J. Cryst. Growth 107 (1991)710-711

[9] Busch H., Fink A., Muller A. J. Appl. Phys. 70(1991)2449-2451 
[10] Gupta A., Jagannathan R.,et al., Appl. Phys. Lett. 52 (1988)2077-2079.

[11] Mcintyre P.C.,Cima M.J.,et al., J.Appl.Phys. 68(1990)4183-4187.

[12] Zhao J., et al., Appl.Phys.Lett. 53(1988)1750-1752.

[13] Panson A.J., et al., Appl.Phys.Lett. 53(1988)1756-1758.

[14] Zhao J., Chern C.S.,et al., J. Cryst.Growth 107(1991)699-703.

[15] Kaul A.R., J. Vses. Khim. Obschestva 34 (1989)492-503.

[16] Rubtsov E.M., Mishin V.Ya. in Teoteticheskaya i prikladnaya khimiya $\beta$-diketonatov metallov (Nauka, Moskva, 1985)pp.136-138.

[17] Mazurenko E.A., Bublik J.N., Volkov S.V., Ukr.Khim.Jour. 45 (1979)591-596.

[18] Mazurenko E.A. et al., "Ultrasonic effect on crystallization processes of Y-Ba-Cu-O films" San Francisco, CA, The Third International Ceramic Science and Technology Congress, November 1-4 1992, p.21. 